\title{
Cardiovascular risk in women with type 2 diabetes mellitus and prediabetes: is it indeed higher than men?
}

\author{
Panagiotis Anagnostis, Azeem Majeed ${ }^{\mathbf{1}}$, Desmond G Johnston and lan F Godsland \\ Division of Diabetes, Endocrinology and Metabolism, Department of Medicine, Diabetes Endocrinology and \\ Metabolic Medicine, Faculty of Medicine, Imperial College London, Room G1, Norfolk Place, St Mary's Campus, \\ London W2 1NH, UK and 'Department of Primary Care and Public Health, Faculty of Medicine, Imperial College \\ London, London, UK
}

Correspondence

should be addressed

to $P$ Anagnostis

Email

anagnwstis.pan@yahoo.gr

\begin{abstract}
The relative risk for cardiovascular disease (CVD) events and mortality in diabetic women (in comparison with non-diabetic women) is believed to be greater than that in diabetic men. However, the absolute risk for CVD mortality and morbidity does not appear to be higher in women. In general, there is heterogeneity between studies, and whether there is any definite difference in the CVD risk between sexes at any level of glycaemia is not known. The same arguments also apply when comparing the CVD risk factors, such as lipid profiles and systemic inflammation indices, which seem to be worse in women than in men with diabetes mellitus (DM). The same questions emerge at any given glycaemic state: are women at worse risk and do they have a worse risk factor profile than men? These issues have yet to be resolved. Similar, though less extensive, data have been reported for prediabetes. Furthermore, women with DM are suboptimally treated compared with men regarding lipid and blood pressure targets. Large prospective studies representative of the general population are therefore needed to define the differences between sexes regarding CVD events and mortality at a given glucose level and after adjusting for any other confounders.
\end{abstract}

\section{Introduction}

Diabetes mellitus (DM) is associated with increased morbidity and mortality from cardiovascular disease (CVD) in both sexes $(1,2)$. Male sex is also an independent CVD risk factor in the general population - in effect women enjoy protection from CVD relative to men (3). On the other hand, it has been repeatedly suggested in the literature that, on developing DM, women lose their relative protection from $\mathrm{CVD}$ and that, relative to their respective sexes free of $\mathrm{DM}$, women with $\mathrm{DM}$ are at a higher risk of CVD than men with $\operatorname{DM}(1,3)$.

There are two major questions regarding this apparent interaction between DM and CVD risk in women: i) what is the absolute risk of CVD in women compared with men with DM? and ii) does female sex really have a specific interaction with DM to increase the CVD risk beyond the effect of DM in men? To resolve these issues, we need to distinguish studies that have reported risks of CVD in those with DM relative to those free of DM from studies that have reported absolute rather than relative risks and to establish reliable estimates of absolute risk of CVD among men and women with DM. These comparisons need to take into account differences in risk factors that might contribute to the differences in relative and absolute risks observed. A definitive evaluation of the extent to which female sex interacts with DM to augment CVD risk must, however, come from a comparison of (c) 2014 European Society of Endocrinology Printed in Great Britain
Published by Bioscientifica Ltd. 
absolute risks of CVD in women and men at the same levels of glycaemia, with matching for other risk factors. As will be described, such a study has yet to be done.

In general, most studies of CVD risk in women and men with diabetes have been undertaken in crosssectional or prospective cohorts. Relative risks have been expressed in terms of risk in women with DM relative to women free of DM and similarly for men. In general, these studies indicate a higher relative CVD risk in diabetic women than in men. One of the earliest studies specifically addressing CVD risk according to sex in patients with DM came from Evans County, Georgia, USA (4). This analysis was published in 1980 and included 1284 men and 1420 women, with a mean duration of 4.5 years. The risk of CVD mortality relative to their respective sexes free of DM was higher for women than men (standardised mortality ratio 2.8 vs 1.0 , respectively, after adjusting for traditional CVD risk factors), thus supporting the possibility of a specific interaction between female sex and DM in CVD risk. Other major studies evaluating relative risks of CVD between women and men with and without DM have included the Rancho Bernardo and Framingham Studies $(5,6,7)$. Overall, the reported relative risk for death from CVD in these influential studies was 3.3- to 4.9-fold higher in women with DM compared with women free of DM, whereas the equivalent figures in men were approximately two- to 2.5 -fold $(4,5$, 6 , 7). Although CIs for these relative risks generally overlapped between women and men, these findings support a higher relative risk for death from CHD in women than in men. After adjustment for well-known CVD risk factors such as age, blood pressure (BP), total cholesterol (TC) and smoking, the difference seems to remain significant, although slightly decreased (3.3-3.8 for women and 1.7-2.4 for men) $(4,5,6,7)$.

However, findings have not been entirely consistent. A few studies, such as the large Asia Pacific Cohort Studies Collaboration (2), did not show any difference between sexes in deaths from CHD, cerebrovascular disease or other CVDs, irrespective of ethnicity. Moreover, although these studies have considered the risk of CVD events in those initially free of CVD, some authors found no sex difference according to DM in risk of recurrent CVD in women and men with existing CVD (8).

These inconsistencies have been largely resolved by two meta-analyses of studies of sex differences in the relative risk of CVD between women and men with DM. In the first, published in 2000, data from ten studies (>70000 patients) were included. This meta-analysis showed that the relative risk of DM-related CHD resulting in death was higher in women than in men $(2.54$ (95\% CI: 2.08-3.09) and 1.76 (95\% CI: 1.51-2.05) respectively), which did not change much, when the studies that had adjusted for CVD risk factors were included (2.58 (95\% CI: 2.05-3.26) for women and 1.85 (1.47-2.33) for men) (9). After excluding three studies in which patients with prior CHD were excluded, the difference between sexes remained but was not significant, the pooled relative risks being $2.37(1.83-3.07)$ for women and 1.85 (1.43-2.39) for men $(P=0.183)$ (9). The second metaanalysis was published in 2006 and included data from 37 prospective cohort studies (447 064 patients). Out of these studies, eight were adjusted only for age. Excluding these, to include studies that were adjusted for at least age, BP, TC and smoking, the relative risk for diabetes-related fatal CVD was $50 \%$ higher in women than in men (pooled ratio of the relative risks: 1.46 , 95\% CI: 1.14-1.88) (1), after adjustment of multiple CVD factors. The same group has recently published an updated meta-analysis report including data from 64 cohorts (858 507 individuals and 28203 incident CHD events). The new meta-analysis showed a relative risk of 2.82 (CI: 2.35-3.38) and 2.16 (CI: 1.82-2.56) in women and men, respectively, yielding a $44 \%$ greater multiple-adjusted relative risk ratio in women with DM compared with men with DM (10).

Moreover, in a recent study from the UK Clinical Practice Research Datalink (CPRD) including patients with a history of myocardial infarction (MI), women with type 2 DM had a $41 \%$ higher risk of developing a subsequent MI compared with non-diabetic women, after adjusting for traditional CVD factors. This risk was significantly higher than in men (23\% higher risk in men with DM vs those without DM) (11). Furthermore, a recent meta-analysis of three large cohorts of diabetic patients without CHD at enrolment, the high-risk GeneSTAR Study, the MultiEthnic Study of Atherosclerosis (MESA) and National Health and Nutrition Examination Survey III (NHANES III) Mortality Follow-up Study, demonstrated that women with DM compared with women without DM had approximately four times higher risk of CHD events, whereas no significant differences were noticed for men (adjusted hazard ratio (HR): 3.61, 95\% CI: $1.97-6.61$ for women and HR: 1.17, 95\% CI: 0.71-1.94 for men) (12). Accumulating evidence from studies of relative risks of CVD in women and men with CVD, therefore, supports a significantly greater risk in women.

Studies exploring CVD risk differentials between men and women with DM, in terms of risks relative to their non-diabetic counterparts, are summarised in Table 1. 
Table 1 Studies showing relative risk of CVD death according to sex and diabetes status (studies with 95\% Cls shown were adjusted for CVD risk factors). Data in parentheses refer to $\mathrm{Cls}$ (where available).

\begin{tabular}{|c|c|c|}
\hline References & $\begin{array}{l}\text { RR in men with } \\
\text { DM/men without DM }\end{array}$ & $\begin{array}{l}\text { RR in women with } \\
\text { DM/women without DM }\end{array}$ \\
\hline (1) & 1.99 (1.69-2.35) & $3.12(2.34-4.17)$ \\
\hline (2) & $2.54(1.84-3.49)^{*}$ & $2.03(1.60-2.59)^{*}$ \\
\hline & $2.04(1.46-2.84)^{\dagger}$ & $2.0(1.37-2.92)^{\dagger}$ \\
\hline (4) & 1.0 & 2.8 \\
\hline (5) & 1.9 & 3.3 \\
\hline (6) & 2.4 & 3.5 \\
\hline (7) & 1.7 & 3.3 \\
\hline (9) & $1.85(1.47-2.33)$ & $2.58(2.05-3.26)$ \\
\hline (10) & $2.16(1.82-2.56)$ & $2.82(2.35-3.38)$ \\
\hline$(11)^{a}$ & $1.23(1.14-1.34)$ & $1.41(1.27-1.56)$ \\
\hline (12) & $1.17(0.71-1.94)$ & $3.61(1.97-6.61)$ \\
\hline (14) & $2.1(1.3-3.3)$ & $3.8(2.2-6.6)$ \\
\hline$(15)^{a}$ & $2.67(2.43-2.95)$ & $4.26(3.68-4.94)$ \\
\hline (16) & $1.3(0.9-2)$ & $1.8(1.2-2.7)$ \\
\hline (17) & $2.75(2.05-3.70)$ & $9.54(5.39-16.87)$ \\
\hline (19) & 3.79 & 4.72 \\
\hline (20) & $2.31(1.91-2.85)$ & $2.92(2.22-3.84)$ \\
\hline
\end{tabular}

$C V D$, cardiovascular disease; CHD, coronary heart disease; $A R$, absolute risk; $\mathrm{DM}$, diabetes mellitus; $\mathrm{RR}$, relative risk.

${ }^{\text {a }}$ This study refers to the risk of myocardial infarction.

* for death from CHD; ${ }^{\dagger}$ for death from stroke.

Studies have also been carried out exploring whether a history of DM or a history of CHD confers a greater risk of a subsequent CHD event and these studies include findings relevant to a possible interaction between female sex and DM in CHD risk. A Finnish study involving 18 years of follow-up explored HRs for a CHD event in women and men with DM and no history of CHD compared with those with no DM but with established CHD. In women, the HR was 3.5 (95\% CI: 1.8-6.8), whereas in men it was 1.5 (95\% CI: 1.0-2.2). These findings imply that, in women, DM confers a $350 \%$ increase in the risk of CHD compared with established CHD, whereas, in men, the increase is only 50\% (13). This inverse relationship was also confirmed by the pooled analysis of data from the Framingham Heart Study and the Framingham Offspring Study, in which, after multivariate adjustment, the HR of CHD mortality (relative to those free of both DM and CHD, after adjustment for multiple CVD risk factors) in diabetic men without established CHD was 2.1 (95\% CI: 1.3-3.3) vs 4.2 (95\% CI: 3.2-5.6) in those with prior CHD without DM. The corresponding HRs in women were 3.8 (95\% CI: 2.2-6.6) and 1.9 (95\% CI: 1.1-3.4) respectively (14). These findings suggest that, in this study, in women DM confers a $200 \%$ increase in the risk of death from CHD compared with established CHD (3.8/1.9), whereas in men DM confers only half the risk of established CHD (2.1/4.2). Furthermore, the INTERHEART, a large case-control study including >12000 cases of acute MI, considered that DM was more strongly associated with $\mathrm{MI}$ in women than in men (odds ratio (OR): 4.3, 95\% CI: 3.5-5.2 vs OR: 2.7 , 95\% CI: 2.7-3.0) (15). However, not all studies imply such an excessive risk associated with DM in women. In the Hoorn Study, there was an equal risk of CVD events between diabetic women without prior CVD and nondiabetic women with CVD (adjusted HR: 1.0; 95\% CI: 0.6-1.7), whereas the risk in diabetic men without prior CVD was lower than that in those with established CVD without DM (adjusted HR: 0.5; 95\% CI, 0.3-0.9) (16). Nevertheless, again, the balance of evidence from studies of DM and existing CVD as risk factors for subsequent CVD favours increased risk among women.

Studies exploring CVD risk differentials in men and women depending on DM or established CVD are summarised in Table 2.

Clearly, when considered in terms of risks relative to those free of DM, women with DM appear to be at a greater risk of CVD than men. Interestingly, consideration of relative risks in the presence or absence of DM in men relative to women highlights how the greater risk in women with DM relative to women free of DM involves a convergence with the risk in men with DM from a markedly greater divergence in the risk from men free of DM. In two studies in which these risks were presented $(5,17)$, men with DM were at a higher risk of CVD relative to women with $\mathrm{DM}$, but in the absence of DM, this risk differential was even greater. However, this still leaves open the issue as to how absolute risk differs. The purpose of this review is to clarify whether there is any increased absolute risk of CVD mortality in women with DM

Table 2 Studies showing relative risk of CVD death according to sex, diabetes and CVD status (studies with $95 \% \mathrm{Cls}$ shown were adjusted for CVD risk factors). Data in parentheses refer to Cls (where available).

\begin{tabular}{|c|c|c|}
\hline References & $\begin{array}{l}\text { RR in men with } \\
\text { DM and without } \\
\text { CVD/men with CVD } \\
\text { and without DM }\end{array}$ & $\begin{array}{l}\text { RR in women with } \\
\text { DM and without } \\
\text { CVD/women with } \\
\text { CVD and without DM }\end{array}$ \\
\hline (13) & $1.5(1.0-2.2)$ & $3.5(1.8-6.8)$ \\
\hline (16) & $0.5(0.3-0.9)$ & $1.0(0.6-1.7)$ \\
\hline
\end{tabular}

CVD, cardiovascular disease; CHD, coronary heart disease; $A R$, absolute risk $\mathrm{DM}$, diabetes mellitus; $\mathrm{RR}$, relative risk. 
compared with men and explores potential mechanisms for such an association, if any.

\section{Are women at increased absolute risk?}

The question that emerges from all these data is whether women are indeed at an increased absolute CVD risk at a given diabetic state compared with men or whether studies are simply pooling women at high risk due perhaps to a longer duration of their disease, which may have a greater impact on the development of atherosclerotic disease along with other established CVD risk factors. Very few studies have indeed looked into the difference regarding absolute risk between diabetic sexes and have made adjustments only for well-known confounding risk factors, such as age. These studies have yielded different results, either a male or a female predominance or no difference at all.

A large multicentre Spanish prospective study, the Barbanza Diabetes study, including 1423 consecutive patients diagnosed with DM with a mean follow-up period of 45 months, showed no difference in survival (either from CVD death or from death from all causes) between diabetic men and women and in a multivariate analysis, that included age, CVD, albuminuria, treatment with diuretics and sex as independent variables, all variables except sex were independent predictors of mortality (18). A prospective study from Finland including type 2 diabetic and non-diabetic patients without prior CVD and with a follow-up of 13 years demonstrated that the sex gap of increased rates of CHD mortality and major CHD events in non-diabetic males compared with females was abolished among diabetic subjects (17). This study indicated different predictors of CHD between sexes (see below). A larger proportion of DM-related CHD risk was due to DM itself in women, indicating a stronger effect of DM in women. These three studies support no difference in the absolute CVD risk between men and women with DM, illustrating the pattern of absolute risk that underlies the differences in relative risk, which have been described previously. The aforementioned meta-analysis of the three cohorts (GeneSTAR, MESA and NHANES III) also calculated the absolute risks between sexes both in DM and non-DM states. The adjusted HR for CHD events was similar between the two sexes with DM (HR: 0.89, 95\% CI: 0.43-1.83), whereas it was higher in men without DM compared with women without DM (HR: 2.43 , 95\% CI: 2.19-3.88) (12).

In an earlier study, non-diabetic men had almost three times the age-adjusted CHD death rate of non-diabetic women, which was reduced to twofold in those with diabetes. The magnitude of the death rates was such, however, that the risk in women with diabetes relative to those free of diabetes was substantially greater than that for men. The findings of this study explain the aforementioned difference in relative risk, as the higher absolute risk in men without DM than women compared with absolute risks in those with diabetes results in a greater risk in women (5). This pattern was also displayed by the results of a previous study showing also a greater absolute risk for death from CHD in men than in women with DM and asymptomatic hyperglycaemia after a 9-year follow-up period, despite a higher relative CVD risk in women, adjusted for age and other confounding factors (19). The findings of the above studies were confirmed by a meta-analysis of 16 prospective studies and mean follow-up time of 14 years, published in 2002, which demonstrated a male predominance in the absolute risk for deaths from CHD attributable to diabetes at every age except for the elderly ( $>85$ years), although most studies that reported CHD mortality were conducted in white populations. However, the OR for CHD mortality, nonfatal MI and CVD mortality tended to be higher among women with diabetes compared with men relative to their non-diabetic counterparts, but were not statistically significant, after adjusting for age, hypertension, TC levels and smoking (20). An early meta-analysis of 12 studies explored sex differences in the risk for CHD mortality and MI in men relative to women with non-insulin-dependent DM (NIDDM) and in those free of NIDDM (21). This study demonstrated that NIDDM reduces the male predominance in CHD mortality, although remaining significantly higher than in women (OR: 1.46 in NIDDM vs 2.29 in nondiabetes), which would be consistent with the absolute risk in women with NIDDM converging but not exceeding the absolute risk in men with NIDDM. However, this effect was not apparent for prevalent MI (21).

Similar results indicating a male predominance with respect to the risk of stroke were shown by two studies, one from Finland and the other from the USA. The former showed that the risk for ischaemic stroke was greater in males than in females with DM and it further increased with advancing age, although this difference between the two sexes was not substantial in the non-diabetic state. However, the sex difference regarding CHD was larger in non-diabetic subjects than in diabetic subjects (22). The latter study on sex differences regarding the incidence of stroke showed that for a given level of HbA1c males had a higher risk for stroke. This absolute sex difference existed only among patients with baseline HbA1c 
Table 3 Studies showing data about absolute (events/1000 per 10 years) or relative risk of CVD death between diabetic sexes (most of them adjusted for CVD risk factors). Data in parentheses refer to Cls (where available).

\begin{tabular}{|c|c|c|c|c|c|c|}
\hline References & $\begin{array}{l}\text { AR in men } \\
\text { with DM }\end{array}$ & $\begin{array}{c}\text { AR in men } \\
\text { without DM }\end{array}$ & $\begin{array}{c}\text { AR in women } \\
\text { with DM }\end{array}$ & $\begin{array}{l}\text { AR in women } \\
\text { without DM }\end{array}$ & $\begin{array}{c}\text { RR in men with } \\
\text { DM/men } \\
\text { without DM }\end{array}$ & $\begin{array}{c}\text { RR in women with } \\
\text { DM/women } \\
\text { without DM }\end{array}$ \\
\hline (5) & 108 & 53 & 87 & 13 & 2.4 & 3.5 \\
\hline (17) & 363 & 116 & 316 & 18 & 2.8 & 9.5 \\
\hline$(12)^{a}$ & & & & & 1.17 & 3.61 \\
\hline GeneSTAR & 12.86 & 11.22 & 17.65 & 4.27 & & \\
\hline MESA & 9.71 & 5.64 & 7.34 & 1.66 & & \\
\hline NHANES & 1.83 & 0.88 & 2.37 & 0.40 & & \\
\hline (18) & 91 & & 6 & & & \\
\hline (19) & 122 & 25 & 31 & 5 & 3.8 & 4.7 \\
\hline (26) & 277 & & 810 & & & \\
\hline
\end{tabular}

CVD, cardiovascular disease; CHD, coronary heart disease; AR, absolute risk; DM, diabetes mellitus; RR, relative risk. ${ }^{a}$ This study refers to the risk of myocardial infarction.

$<7 \%(53 \mathrm{mmol} / \mathrm{mol})$ and $<8 \%(64 \mathrm{mmol} / \mathrm{mol})$ during follow-up. Nevertheless, a positive association between HbA1c and the risk was shown only for women but not for men with DM and remained significant after adjustment for possible confounding factors, such as smoking, socioeconomic status, BMI, LDL cholesterol (LDLC), renal function, and use of antihypertensive, and lipid- and glucose-lowering agents (23). However, a recent metaanalysis including data from 64 cohort studies (775 385 individuals) showed a higher risk for fatal and non-fatal stroke in women with DM compared with men with DM (1.27 (95\% CI: $\left.1.10-1.46 ; I^{2}=0 \%\right)$ ), with no evidence of publication bias (24).

Moreover, a recent prospective study including 17510 African American and 12592 white patients with type 2 DM did not find any sex difference in CHD risk at a given HbA1c level (25).

We found only one study showing a higher absolute risk in women compared with men with DM. This was a prospective study conducted in The Netherlands, which included patients with type 2 DM without prior CVD. After a mean follow-up time of 4.7 years, female sex was associated with a higher absolute risk for CVD events and death from CVD than male sex. This risk was 3.19 times higher in women in unadjusted analysis and, after adjusting for established CVD risk factors (such as age, systolic BP, BMI, total-to-HDL cholesterol (HDLC) ratio, smoking and urinary albumin excretion or retinopathy), it was still increased to over twofold. Nevertheless, the limitations of this study were that it included a relatively small number of patients (46 men and 21 women) and it was confined to normotensive patients with microalbuminuria (26). Studies reporting an absolute risk of
CVD death in diabetic sexes (most of them adjusted for CVD risk factors) are summarised in Table 3.

It seems therefore that a female predominance in the absolute risk for CVD mortality and morbidity cannot be supported by current data. Heterogeneity between studies exists and the main question as to whether there is any definite difference in the CVD risk between sexes at a given glycaemic state cannot be answered yet.

\section{Differences in factors that might contribute to sex differences in CVD risk in DM}

Given the uncertainties regarding any difference between men and women with DM and absolute risk of CVD, an evaluation of differences in CVD risk factors or factors that might affect differences in CVD risk may be informative. Importantly, any difference in CVD risk between men and women with $\mathrm{DM}$ is unlikely to be attributable to the loss of the protective effect of oestrogens in menopause, as the use of hormone replacement therapy, in particular, conjugated equine oestrogens and medroxyprogesterone acetate, did not decrease the CVD risk in women with DM (27).

A common and major finding from most of these studies is the effect of sex on the prevalence of specific CVD risk factors (other than DM). Data from older studies suggest that traditional CHD risk factors are generally better predictors of CVD in women than in men (28). It appears that diabetic women compared with non-diabetic women may have a more severe degree of CVD risk factor abnormalities than their male counterparts or the impact of these factors on CVD mortality may be greater in diabetic women than in men (20). 
In particular, several parameters, such as BMI, TC, LDLC, apolipoprotein B and TG levels and small LDL particles (most of them related to insulin resistance), seem to provide stronger prediction of diabetes-related $\mathrm{CHD}$ events in women than in men $(29,30,31,32)$. Furthermore, differences exist with respect to coagulation factors (higher levels of factor VIII), increased blood viscosity, endothelial dysfunction (higher levels of tissue plasminogen activator) and inflammation, as indicated by higher white cell blood count (28), a CHD and an allcause mortality prognostic factor (33). It must be stated that the sex gap in these factors was significant in diabetic subjects, indicating a predisposition to an increased absolute risk in women $(29,32)$. Conflicting data exist regarding the importance of other CVD risk factors, such as waist circumference, HDLC, very-LDLC, lipoprotein alpha and systolic and diastolic BP $(17,29$, 32, 34, 35, 36, 37, 38). Regarding lipid metabolism, it should be noted that differences in the relevant regulatory genes have been noticed in insulin resistance, such as higher expression of fatty acid translocase/CD36, fatty acid synthase and glycerol-3-phosphate acyltransferase in animal and human studies $(39,40)$. These characteristics suggest a relatively low capacity for substrate utilisation along with a high capacity for fatty acid uptake and synthesis in females, leading to a higher risk of development of fatty liver disease $(39,40)$, which has been considered as an independent CVD risk factor (41). It is not clear whether these lipid differences may also be influenced by menopause, as conflicting data exist as to whether post-menopausal women have indeed a worse lipid profile than their male counterparts, although the female lipid profile becomes more atherogenic after transition from the pre-menopausal to post-menopausal status, converging with the male profile $(42,43)$. In general, most studies suggest a higher CVD risk in post-menopausal women compared with pre-menopausal women, although it has not been well clarified whether a higher risk after transition to menopause is a result of the ageing process or oestrogen deficiency or both (44).

Higher levels of high-sensitivity C-reactive protein (hsCRP), a marker of systemic inflammation, were also reported in diabetic women vs diabetic men, which may be another underlying mechanism for a potential increased CVD risk in women with DM compared with men $(32,45)$. The importance of hsCRP in CVD risk has been supported after the publication of the Justification for the Use of Statins in Prevention: an Intervention Trial Evaluating Rosuvastatin (JUPITER) trial, regarding the effect of a decrease in hsCRP levels by rosuvastatin on CVD risk reduction (46). Interestingly, a stronger association between coronary artery calcification (CAC), a marker of subclinical atherosclerosis, and hsCRP has been shown in diabetic women compared with men (47). Increased systemic inflammation in diabetic women has also been shown by differences in the levels of interleukin 1 receptor antagonist (IL1RA (IL1RN)) and adiponectin compared with diabetic men (45).

Another noteworthy explanation for the disparity between diabetic sexes regarding CVD risk may be the lower adherence to treatment of diabetic women than men $(35,48)$, the fact that women are managed less aggressively than men, regarding targets of CVD risk factors, mainly lipids and BP $(34,49,50,51,52)$, or that women are more likely to have more than one risk factor (53). There are conflicting data about the difference in achieving HbA1c targets $(17,50,51,52)$. In one study, $46.6 \%$ of diabetic women failed to achieve the goal for systolic BP vs $41.2 \%$ of diabetic men. The respective percentages for failure in reaching LDLC targets were 28.3 vs $22.4 \%$ (52). Men with DM seem to receive aspirin, statins or antihypertensive drugs more frequently than women (in one study $35 \%$ of women with DM were prescribed a statin compared with $45 \%$ of men (54) and 23 vs 33\% in another (55)). Similar findings were reported from the United Kingdom Prospective Diabetes study (UKPDS), where diabetic women were significantly less likely to use aspirin than diabetic men (56). An analysis of data from the GPRD also showed that women with DM had persistently worse lipid control and were less likely to receive a statin than men with DM, although differences in BP disappeared after implementation of the Quality and Outcomes Framework (57).

Regarding DM itself, conflicting data exist on the significance of HbA1c as a CVD risk factor between sexes $(28,30)$. A recent study has shown that each $1 \%$ increase in baseline HbA1c was associated with a 5\% increased risk of stroke in women and 1\% increased risk of stroke in men with DM (24). However, postprandial glucose is a stronger predictor of CVD in diabetic women than in men $(58,59)$. Women with DM also have higher levels of advanced glycation end products (AGEs), another predictor of CVD risk (60). Moreover, DM has a more deleterious effect on the endothelium in women, as it is associated with increased expression or activation of oestrogen receptor beta (ER $\beta$ (ESR2)) over ER $\alpha$ (ESR1); this results in higher oxidative stress and proinflammatory state, as indicated by decrease in nitric oxide and increase in reactive oxygen species and endothelin 1 production, and also increases the receptors for AGEs (61). Another parameter 
contributing to a sex difference in CVD risk may also be the difference in intervention strategies, such as acute reperfusion therapy in ST elevation MI, which seems to be less often used in women than in men, independent of other confounders such as pre-hospital delay, atypical symptoms or DM (62). Sex differences in specific situations, such as renal failure (50) and rheumatic disorders such as lupus (63), must also be taken into account. CVD is more prevalent in men with DM and renal failure compared with women, although the latter display a less favourable CVD risk profile and less frequently achieve the treatment targets for HbA1c, lipid and systolic BP (50). Similarly, men with lupus are more likely to suffer from CVD and greater disease activity compared with women with lupus, although data are limited (63). Finally, the contributory effect of some other factors in the CVD risk gap between diabetic sexes has also been demonstrated. Briefly, these include worse autonomic neuropathy indices in women compared with men, which are associated with a higher CVD risk (64), sex difference in presentation of symptoms, more atypical and silent symptoms in women in contrast to the more typical and pronounced manifestations in men (65), differences in exercise capacity and greater impairment in peak exercise capacity in women (66). To the best of our knowledge, no evidence exists with respect to the effect of gestational diabetes on sex differences in the offspring in terms of CVD risk.

Taking all these data together, a difference in CVD risk profile seems to exist in diabetic women compared with diabetic men, as indicated by a worse lipid profile, higher systemic inflammation, lower adherence to treatment and greater failure to achieve lipid and BP targets and a different impact of DM on the endothelium. Whether this is also translated in a greater absolute CVD risk remains yet to be verified.

\section{Existing data regarding prediabetes}

For prediabetes, available data are scarce regarding studies exploring sex differences in absolute or relative risk for CVD mortality. Most such studies have addressed the prevalence of CVD risk factors and surrogate markers of atherosclerosis rather than CVD events or CVD mortality in both sexes with prediabetes. Furthermore, different definitions of prediabetes were used, either as impaired fasting glucose (IFG) or impaired glucose tolerance (IGT) or both. The most important study was published a decade ago and extended the issue of sex difference in all-cause and CVD mortality to various degrees of hyperglycaemia.
With a population of 8172 men and 9407 women without a history of DM and a median follow-up time of 8.3 years, the authors showed that at a given glycaemic state the absolute risk was higher in men than in women, but this difference narrowed when progressing from normoglycaemia to impaired glucose regulation and newly diagnosed diabetes. Interestingly, the relative risk of CVD mortality was higher in women with DM that had been newly diagnosed relative to normoglycaemic women in comparison with their male counterparts (67). Another study looking into sex differences in surrogate markers of atherosclerosis in normoglycaemia, prediabetes (IFG and/or IGT) and diabetes found that women had higher adiponectin levels than men in all these three glycaemic states and lower hsCRP and ILRA levels in prediabetic and diabetic states (45).

Regarding sex differences in terms of relative risk in prediabetes, a large prospective study published in 1998 with a 7-year follow-up period showed a significantly increased risk of fatal CVD and CHD events in women with IGT compared with non-diabetic women, a difference which was not shown in their male counterparts. HRs in women were 2.6 and 2.9, respectively, for fatal CVD and CHD, after adjusting for multiple CVD risk factors (68). Another study demonstrated a positive association between fasting plasma glucose and CAC. Patients with IFG have significantly higher CAC scores, especially men, but when the age- and sex-specific 75th percentile was used as the cut-off point for CAC, the association became stronger in women (69). In a similar way to IGT, IFG also seems to be strongly associated with CVD risk in women, in contrast to men, as the relative risk for recurrent CVD events after surviving an acute $\mathrm{MI}$ is twofold in women with IFG compared with normoglycaemic women (HR: 1.96), an association that was not found in men (70).

With regard to CVD risk factors or surrogate atherosclerotic indices, conversion from prediabetes to $\mathrm{DM}$ is associated with an increased BMI, fasting insulin, TG and BP and lower HDLC, differences that are greater in women than men (71). Furthermore, it has been shown that women who progress from normoglycaemia to prediabetes have worse endothelial dysfunction than those who do not, as demonstrated by the higher levels of biomarkers of endothelial function (E-selectin and soluble intracellular adhesion molecule 1), fibrinolysis/ thrombosis (plasminogen activator inhibitor 1) and hsCRP, and lower adiponectin levels compared with normoglycaemic women. These differences were not significant in men except for hsCRP levels, but they were lower than that in women (72). Another possible 
mechanism underlying the increased relative CVD risk in women with prediabetes may be the increasing left ventricular mass and wall thickness that appears with worsening of glucose intolerance, which is more pronounced in women than in men (73).

A sex gap in favour of females does seem to exist in prediabetes, although the evidence is not strong enough, it involves mainly differences in relative risk and prevalence of CVD risk factors and cardiac structure deformities, both in IFG and IGT states.

\section{Conclusions}

An emerging greater relative risk for CVD events and death from CVD seems to exist in women with DM (in comparison with women without DM) than in diabetic men. Accordingly, the growing body of evidence from comparisons of CVD risk in those with DM relative to those free of DM, whether with or without existing CVD, favours a markedly greater impact of DM in women than in men. However, such a difference does not necessarily mean that DM has a specific interaction with female sex to augment CVD risk. A diagnosis of DM could itself be associated with factors that bias women in favour of exhibiting a higher risk of CVD than might otherwise be the case. With the overall protection from CVD that women enjoy relative to men in mind, clinicians may have been less likely to prescribe BP- or lipid-lowering agents to women or women may be less adherent to such CVD prevention measures than men. Beyond these clinical considerations, selection of women with the same degree of hyperglycaemia as men, as is the case when selecting people according to a diagnosis of DM, could simply result in the selection of groups at equivalent risk. If the total population of women from which the female group has been selected has an overall lower risk of CVD than the total population of men, the relative risk of CVD among women with DM will necessarily be higher than that in men, but this will simply reflect the process of selection rather than any intrinsic interaction between DM and female sex. However, there is no clear evidence for a female predominance in absolute risk. It is perhaps because, to meet the criteria for diabetes, women have further to go from normoglycaemia to prediabetes and $\mathrm{DM}$, and the longer time this may take may be responsible for the accumulation of severe CVD risk factors other than diabetes. What we need are large prospective studies representative of the general population to examine the differences between sexes regarding CVD events and mortality from CVD at a given glucose level and after adjusting for age, diabetes duration and other confounders so as to better clarify the impact of sex on CVD risk among diabetic populations. Of even greater interest would be an interventional study focusing on the differences between the sexes in the effect of glucose regulation on CVD outcomes.

Declaration of interest

The authors declare that there is no conflict of interest that could be perceived as prejudicing the impartiality of the review.

\section{Funding}

This review did not receive any specific grant from any funding agency in the public, commercial or not-for-profit sector.

\section{Acknowledgements}

Imperial College London is grateful for support from the NW London NIHR Collaboration for Leadership in Applied Health Research and Care (CLAHRC) and the Imperial NIHR Biomedical Research Centre (BRC).

\section{References}

1 Huxley R, Barzi F \& Woodward M. Excess risk of fatal coronary heart disease associated with diabetes in men and women: meta-analysis of 37 prospective cohort studies. BMJ 2006332 73-78. (doi:10.1136/bmj. 38678.389583.7C)

2 Woodward M, Zhang X, Barzi F, Pan W, Ueshima H, Rodgers A, MacMahon S \& Asia Pacific Cohort Studies Collaboration. The effects of diabetes on the risks of major cardiovascular diseases and death in the Asia-Pacific region. Diabetes Care 200326 360-366. (doi:10.2337/ diacare.26.2.360)

3 Jousilahti P, Vartiainen E, Tuomilehto J \& Puska P. Sex, age, cardiovascular risk factors, and coronary heart disease: a prospective follow-up study of 14786 middle-aged men and women in Finland. Circulation 199999 1165-1172. (doi:10.1161/01.CIR.99.9.1165)

4 Heyden S, Heiss G, Bartel AG \& Hames CG. Sex differences in coronary mortality among diabetics in Evans County, Georgia. Journal of Chronic Diseases 198033 265-273. (doi:10.1016/0021-9681(80)90021-1)

5 Barrett-Connor EL, Cohn BA, Wingard DL \& Edelstein SL. Why is diabetes mellitus a stronger risk factor for fatal ischemic heart disease in women than in men? The Rancho Bernardo Study. Journal of the American Medical Association 1991265 627-631. (doi:10.1001/jama. 1991.03460050081025)

6 Barrett-Connor E \& Wingard DL. Sex differential in ischemic heart disease mortality in diabetics: a prospective population-based study. American Journal of Epidemiology 1983118 489-496.

7 Kannel WB \& McGee DL. Diabetes and glucose tolerance as risk factors for cardiovascular disease: the Framingham Study. Diabetes Care 19792 120-126. (doi:10.2337/diacare.2.2.120)

8 Ogita M, Miyauchi K, Dohi T, Wada H, Tuboi S, Miyazaki T, Nishino A, Yokoyama T, Kojima T, Yokoyama K et al. Gender-based outcomes among patients with diabetes mellitus after percutaneous coronary intervention in the drug-eluting stent era. International Heart Journal 201152 348-352. (doi:10.1536/ihj.52.348)

9 Lee WL, Cheung AM, Cape D \& Zinman B. Impact of diabetes on coronary artery disease in women and men: a meta-analysis of prospective studies. Diabetes Care 200023 962-968. (doi:10.2337/ diacare.23.7.962 
10 Peters SA, Huxley RR \& Woodward M. Diabetes as risk factor for incident coronary heart disease in women compared with men: a systematic review and meta-analysis of 64 cohorts including 858,507 individuals and 28,203 coronary events. Diabetologia 201457 1542-1551. (doi:10.1007/s00125-014-3260-6)

11 Liang H, Vallarino C, Joseph G, Manne S, Perez A \& Zhang S. Increased risk of subsequent myocardial infarction in patients with type 2 diabetes mellitus: a retrospective cohort study using the U.K. General Practice Research Database. Diabetes Care 20143 1329-1337. (doi:10.2337/dc13-1953)

12 Kalyani RR, Lazo M, Ouyang P, Turkbey E, Chevalier K, Brancati F, Becker D \& Vaidya D. Sex differences in diabetes and risk of incident coronary artery disease in healthy young and middle-aged adults. Diabetes Care 201437 830-838. (doi:10.2337/dc13-1755)

13 Juutilainen A, Lehto S, Rönnemaa T, Pyörälä K \& Laakso M. Type 2 diabetes as a "coronary heart disease equivalent": an 18-year prospective population-based study in Finnish subjects. Diabetes Care 200528 2901-2907. (doi:10.2337/diacare.28.12.2901)

14 Natarajan S, Liao Y, Cao G, Lipsitz SR \& McGee DL. Sex differences in risk for coronary heart disease mortality associated with diabetes and established coronary heart disease. Archives of Internal Medicine 2003 163 1735-1740. (doi:10.1001/archinte.163.14.1735)

15 Anand SS, Islam S, Rosengren A, Franzosi MG, Steyn K, Yusufali AH, Keltai M, Diaz R, Rangarajan S, Yusuf S et al. Risk factors for myocardial infarction in women and men: insights from the INTERHEART study. European Heart Journal 200829 932-940. (doi:10.1093/eurheartj/ ehn018)

16 Becker A, Bos G, de Vegt F, Kostense PJ, Dekker JM, Nijpels G, Heine RJ, Bouter LM \& Stehouwer CD. Cardiovascular events in type 2 diabetes: comparison with nondiabetic individuals without and with prior cardiovascular disease, 10-year follow-up of the Hoorn Study. European Heart Journal 200324 1406-1413. (doi:10.1016/S0195668X(03)00197-0)

17 Juutilainen A, Kortelainen S, Lehto S, Rönnemaa T, Pyörälä K \& Laakso M. Gender difference in the impact of type 2 diabetes on coronary heart disease risk. Diabetes Care 200427 2898-2904. (doi:10.2337/diacare.27.12.2898)

18 Vidal-Pérez R, Otero-Raviña F, Grigorian-Shamagian L, Parga-García V, Eirís-Cambre MJ, de Frutos-de Marcos C, Caneda-Villar C, de la FuenteMariño R, Ramos-González A, González-Juanatey JR et al. Sex does not influence prognosis in diabetic patients. The Barbanza Diabetes study. Revista Española de Cardiología 201063 170-180. (doi:10.1016/S03008932(10)70035-X)

19 Pan WH, Cedres LB, Liu K, Dyer A, Schoenberger JA, Shekelle RB, Stamler R, Smith D, Collette P \& Stamler J. Relationship of clinical diabetes and asymptomatic hyperglycemia to risk of coronary heart disease mortality in men and women. American Journal of Epidemiology 1986123 504-516.

20 Kanaya AM, Grady D \& Barrett-Connor E. Explaining the sex difference in coronary heart disease mortality among patients with type 2 diabetes mellitus: a meta-analysis. Archives of Internal Medicine 2002162 1737-1745. (doi:10.1001/archinte.162.15.1737)

21 Orchard TJ. The impact of gender and general risk factors on the occurrence of atherosclerotic vascular disease in non-insulindependent diabetes mellitus. Annals of Medicine 199628 323-333. (doi:10.3109/07853899608999089)

22 Hyvärinen M, Tuomilehto J, Laatikainen T, Söderberg S, Eliasson M, Nilsson P \& Qiao Q. The impact of diabetes on coronary heart disease differs from that on ischaemic stroke with regard to the gender. Cardiovascular Diabetology 20098 17. (doi:10.1186/1475-2840-8-17)

23 Zhao W, Katzmarzyk PT, Horswell R, Wang Y, Johnson J \& Hu G. Sex differences in the risk of stroke and HbA1c among diabetic patients. Diabetologia 201457 918-926. (doi:10.1007/s00125-014-3190-3)

24 Peters SA, Huxley RR \& Woodward M. Diabetes as a risk factor for stroke in women compared with men: a systematic review and meta-analysis of 64 cohorts, including 775385 individuals and 12539 strokes. Lancet 2014383 1973-1980. (doi:10.1016/S0140-6736(14)60040-4)

25 Zhao W, Katzmarzyk PT, Horswell R, Wang Y, Johnson J \& Hu G. HbA1c and coronary heart disease risk among diabetic patients. Diabetes Care 201437 428-435. (doi:10.2337/dc13-1525)

26 Zandbergen AA, Sijbrands EJ, Lamberts SW \& Bootsma AH. Normotensive women with type 2 diabetes and microalbuminuria are at high risk for macrovascular disease. Diabetes Care 200629 1851-1855. (doi:10.2337/dc06-0287)

27 Manson JE, Hsia J, Johnson KC, Rossouw JE, Assaf AR, Lasser NL, Trevisan M, Black HR, Heckbert SR, Detrano R et al. Estrogen plus progestin and the risk of coronary heart disease. New England Journal of Medicine 2003349 523-534. (doi:10.1056/NEJMoa030808)

28 Gordon T, Castelli WP, Hjortland MC, Kannel WB \& Dawber TR. Predicting coronary heart disease in middle-aged and older persons. The Framington Study. Journal of the American Medical Association 1977 238 497-499. (doi:10.1001/jama.1977.03280060041018)

29 Wannamethee SG, Papacosta O, Lawlor DA, Whincup PH, Lowe GD, Ebrahim $S$ \& Sattar N. Do women exhibit greater differences in established and novel risk factors between diabetes and non-diabetes than men? The British Regional Heart Study and British Women's Heart Health Study Diabetologia 201255 80-87. (doi:10.1007/s00125-0112284-4)

30 Walden CE, Knopp RH, Wahl PW, Beach KW \& Strandness E Jr. Sex differences in the effect of diabetes mellitus on lipoprotein triglyceride and cholesterol concentrations. New England Journal of Medicine 1984 311 953-959. (doi:10.1056/NEJM198410113111505)

31 Sekerija M, Poljicanin T, Erjavec K, Liberati-Cizmek AM, Prašek M \& Metelko Z. Gender differences in the control of cardiovascular risk factors in patients with type 2 diabetes - a cross-sectional study. Internal Medicine 20121 161-166. (doi:10.2169/internalmedicine.51.6094)

32 Williams K, Tchernof A, Hunt KJ, Wagenknecht LE, Haffner SM \& Sniderman AD. Diabetes, abdominal adiposity, and atherogenic dyslipoproteinemia in women compared with men. Diabetes 200857 3289-3296. (doi:10.2337/db08-0787)

33 Grimm RH Jr, Neaton JD \& Ludwig W. Prognostic importance of the white blood cell count for coronary, cancer, and all-cause mortality. Journal of the American Medical Association 1985254 1932-1937. (doi:10.1001/jama.1985.03360140090031)

34 Goldschmid MG, Barrett-Connor E, Edelstein SL, Wingard DL, Cohn BA \& Herman WH. Dyslipidemia and ischemic heart disease mortality among men and women with diabetes. Circulation 199489 991-997. (doi:10.1161/01.CIR.89.3.991)

35 Kautzky-Willer A, Kamyar MR, Gerhat D, Handisurya A, Stemer G, Hudson S, Luger A \& Lemmens-Gruber R. Sex-specific differences in metabolic control, cardiovascular risk, and interventions in patients with type 2 diabetes mellitus. Gender Medicine 20107 571-583. (doi:10.1016/j.genm.2010.12.001)

36 Tohidi M, Hatami M, Hadaegh F, Safarkhani M, Harati H \& Azizi F. Lipid measures for prediction of incident cardiovascular disease in diabetic and non-diabetic adults: results of the 8.6 years follow-up of a population based cohort study. Lipids in Health and Disease 201096. (doi:10.1186/1476-511X-9-6)

37 Qasim AN, Martin SS, Mehta NN, Wolfe ML, Park J, Schwartz S, Schutta M, Iqbal N \& Reilly MP. Lipoprotein(a) is strongly associated with coronary artery calcification in type-2 diabetic women. International Journal of Cardiology 2011150 17-21. (doi:10.1016/j.ijcard. 2010.02.021)

38 Tselmin S, Julius U, Müller G, Fischer S \& Bornstein SR. Cardiovascular events in patients with increased lipoprotein (a) - retrospective data analysis in an outpatient department of lipid disorders. Atherosclerosis. Supplements 200910 79-84. (doi:10.1016/S1567-5688(09)71817-3)

39 Ameen C, Linden D, Larsson BM, Mode A, Holmäng A \& Oscarsson J. Effects of gender and $\mathrm{GH}$ secretory pattern on sterol regulatory elementbinding protein-1c and its target genes in rat liver. American Journal of 
Physiology. Endocrinology and Metabolism 2004287 E1039-E1048. (doi:10.1152/ajpendo.00059.2004)

40 Simoneau JA, Veerkamp JH, Turcotte LP \& Kelley DE. Markers of capacity to utilize fatty acids in human skeletal muscle: relation to insulin resistance and obesity and effects of weight loss. FASEB Journal 199913 2051-2060.

41 Athyros VG, Tziomalos K, Gossios TD, Griva T, Anagnostis P, Kargiotis K, Pagourelias ED, Theocharidou E, Karagiannis A, Mikhailidis DP et al. Safety and efficacy of long-term statin treatment for cardiovascular events in patients with coronary heart disease and abnormal liver tests in the Greek Atorvastatin and Coronary Heart Disease Evaluation (GREACE) Study: a post-hoc analysis. Lancet 2010 376 1916-1922. (doi:10.1016/S0140-6736(10)61272-X)

42 Schaefer EJ, Lamon-Fava S, Cohn SD, Schaefer MM, Ordovas JM, Castelli WP \& Wilson PW. Effects of age, gender, and menopausal status on plasma low density lipoprotein cholesterol and apolipoprotein B levels in the Framingham Offspring Study. Journal of Lipid Research 1994 35 779-792.

43 Goh VH, Tong TY, Mok HP \& Said B. Differential impact of aging and gender on lipid and lipoprotein profiles in a cohort of healthy Chinese Singaporeans. Asian Journal of Andrology 20079 787-794. (doi:10.1111/ j.1745-7262.2007.00294.x)

44 Bittner V. Menopause, age, and cardiovascular risk: a complex relationship. Journal of the American College of Cardiology $2009 \mathbf{5 4}$ 2374-2375. (doi:10.1016/j.jacc.2009.10.008)

45 Saltevo J, Kautiainen H \& Vanhala M. Gender differences in adiponectin and low-grade inflammation among individuals with normal glucose tolerance, prediabetes, and type 2 diabetes. Gender Medicine 20096 463-470. (doi:10.1016/j.genm.2009.09.006)

46 Ridker PM, Danielson E, Fonseca FA, Genest J, Gotto AM Jr, Kastelein JJ, Koenig W, Libby P, Lorenzatti AJ, MacFadyen JG et al. Rosuvastatin to prevent vascular events in men and women with elevated C-reactive protein. New England Journal of Medicine 2008359 2195-2207. (doi:10.1056/NEJMoa0807646)

47 Qasim AN, Budharaju V, Mehta NN, St Clair C, Farouk S, Braunstein S, Schutta M, Iqbal N, Rader DJ \& Reilly MP. Gender differences in the association of C-reactive protein with coronary artery calcium in type-2 diabetes. Clinical Endocrinology 201174 44-50. (doi:10.1111/j.13652265.2010.03879.x)

48 Manteuffel M, Williams S, Chen W, Verbrugge RR, Pittman DG \& Steinkellner A. Influence of patient sex and gender on medication use, adherence, and prescribing alignment with guidelines. Journal of Women's Health 201423 112-119. (doi:10.1089/jwh.2012.3972)

49 Kautzky-Willer A, Stich K, Hintersteiner J, Kautzky A, Kamyar MR, Saukel J, Johnson J \& Lemmens-Gruber R. Sex-specific-differences in cardiometabolic risk in type 1 diabetes: a cross-sectional study. Cardiovascular Diabetology 201312 78. (doi:10.1186/1475-2840-12-78)

50 Penno G, Solini A, Bonora E, Fondelli C, Orsi E, Zerbini G, Trevisan R, Vedovato M, Gruden G, Laviola L et al. Gender differences in cardiovascular disease risk factors, treatments and complications in patients with type 2 diabetes: the RIACE Italian multicentre study. Journal of Internal Medicine 2013274 176-191. (doi:10.1111/joim.12073)

51 Ford ES. Trends in the risk for coronary heart disease among adults with diagnosed diabetes in the U.S.: findings from the National Health and Nutrition Examination Survey, 1999-2008. Diabetes Care 201134 1337-1343. (doi:10.2337/dc10-2251)

52 Ferrara A, Mangione CM, Kim C, Marrero DG, Curb D, Stevens M, Selby JV \& Translating Research Into Action for Diabetes Study Group. Sex disparities in control and treatment of modifiable cardiovascular disease risk factors among patients with diabetes: Translating Research Into Action for Diabetes (TRIAD) Study. Diabetes Care 200831 69-74. (doi:10.2337/dc07-1244)

53 Steingart RM, Packer M, Hamm P, Coglianese ME, Gersh B, Geltman EM, Sollano J, Katz S, Moyé L, Basta LL et al. Sex differences in the management of coronary artery disease. New England Journal of Medicine 1991325 226-230. (doi:10.1056/NEJM199107253250402)
54 Tonstad S, Rosvold EO, Furu K \& Skurtveit S. Undertreatment and overtreatment with statins: the Oslo Health Study 2000-2001. Journal of Internal Medicine 2004255 494-502. (doi:10.1111/j.1365-2796.2004. 01315.x)

55 Winston GJ, Barr RG, Carrasquillo O, Bertoni AG \& Shea S. Sex and racial/ethnic differences in cardiovascular disease risk factor treatment and control among individuals with diabetes in the Multi-Ethnic Study of Atherosclerosis (MESA). Diabetes Care 200932 1467-1469. (doi:10. 2337/dc09-0260)

56 Cull CA, Neil HA \& Holman RR. Changing aspirin use in patients with type 2 diabetes in the UKPDS. Diabetic Medicine 200421 1368-1371. (doi:10.1111/j.1464-5491.2004.01328.x)

57 Hamilton FL, Bottle A, Vamos EP, Curcin V, Ng A, Molokhia M, Majeed A \& Millett C. Impact of a pay-for-performance incentive scheme on age, sex, and socioeconomic disparities in diabetes management in UK primary care. Journal of Ambulatory Care Management 201033 336-349. (doi:10.1097/JAC.0b013e3181f68f1d)

58 Cavalot F, Petrelli A, Traversa M, Bonomo K, Fiora E, Conti M, Anfossi G, Costa G \& Trovati M. Postprandial blood glucose is a stronger predictor of cardiovascular events than fasting blood glucose in type 2 diabetes mellitus, particularly in women: lessons from the San Luigi Gonzaga Diabetes Study. Journal of Clinical Endocrinology and Metabolism 200691 813-819. (doi:10.1210/jc.2005-1005)

59 Barrett-Connor E. The Rancho Bernardo Study: 40 years studying why women have less heart disease than men and how diabetes modifies women's usual cardiac protection. Global Heart 20138 2. (doi:10.1016/ j.gheart.2012.12.002)

60 Mook-Kanamori MJ, Selim MM, Takiddin AH, Al-Homsi H, Al-Mahmoud KA, Al-Obaidli A, Zirie MA, Rowe J, Gherbi WS, Chidiac OM et al. Ethnic and gender differences in advanced glycation end products measured by skin auto-fluorescence. Dermato-Endocrinology 20135 325-330. (doi:10.4161/derm.26046)

61 Dantas AP, Fortes ZB \& de Carvalho MH. Vascular disease in diabetic women: why do they miss the female protection? Experimental Diabetes Research 20122012 570598. (doi:10.1155/2012/570598)

62 Johnston N, Bornefalk-Hermansson A, Schenck-Gustafsson K, Held C, Goodman SG, Yan AT \& Bierman AS. Do clinical factors explain persistent sex disparities in the use of acute reperfusion therapy in STEMI in Sweden and Canada? European Heart Journal. Acute Cardiovascular Care 20132 350-358. (doi:10.1177/ 2048872613496940)

63 Crosslin KL \& Wiginton KL. Sex differences in disease severity among patients with systemic lupus erythematosus. Gender Medicine 20118 365-371. (doi:10.1016/j.genm.2011.10.003)

64 Yufu K, Takahashi N, Okada N, Wakisaka O, Shinohara T, Nakagawa M, Hara M, Yoshimatsu H \& Saikawa T. Gender difference in baroreflex sensitivity to predict cardiac and cerebrovascular events in type 2 diabetic patients. Circulation Journal 201175 1418-1423. (doi:10.1253/ circj.CJ-10-1122)

65 Arslanian-Engoren C, Patel A, Fang J, Armstrong D, Kline-Rogers E, Duvernoy CS \& Eagle KA. Symptoms of men and women presenting with acute coronary syndromes. American Journal of Cardiology 200698 1177-1181. (doi:10.1016/j.amjcard.2006.05.049)

66 Miller TM, Gilligan S, Herlache LL \& Regensteiner JG. Sex differences in cardiovascular disease risk and exercise in type 2 diabetes. Journal of Investigative Medicine 201260 664-670. (doi:10.231/JIM. 0b013e31824b2de6)

$67 \mathrm{Hu}$ G \& DECODE Study Group. Gender difference in all-cause and cardiovascular mortality related to hyperglycaemia and newlydiagnosed diabetes. Diabetologia 200346 608-617.

68 Barrett-Connor E \& Ferrara A. Isolated postchallenge hyperglycemia and the risk of fatal cardiovascular disease in older women and men. The Rancho Bernardo Study. Diabetes Care 199821 1236-1239. (doi:10.2337/diacare.21.8.1236)

69 Moebus S, Stang A, Möhlenkamp S, Dragano N, Schmermund A, Slomiany U, Hoffmann B, Bauer M, Broecker-Preuss M, Mann K et al. 
Association of impaired fasting glucose and coronary artery calcification as a marker of subclinical atherosclerosis in a populationbased cohort - results of the Heinz Nixdorf Recall Study. Diabetologia 200952 81-89. (doi:10.1007/s00125-008-1173-y)

70 Donahue RP, Dorn JM, Stranges S, Swanson M, Hovey K \& Trevisan M. Impaired fasting glucose and recurrent cardiovascular disease among survivors of a first acute myocardial infarction: evidence of a sex difference? The Western New York experience Nutrition, Metabolism, and Cardiovascular Diseases 201121 504-511. (doi:10.1016/j.numecd. 2009.11.012)

71 Haffner SM, Miettinen H \& Stern MP. Relatively more atherogenic coronary heart disease risk factors in prediabetic women than in prediabetic men. Diabetologia 199740 711-717. (doi:10.1007/ s001250050738)

72 Donahue RP, Rejman K, Rafalson LB, Dmochowski J, Stranges S \& Trevisan M. Sex differences in endothelial function markers before conversion to pre-diabetes: does the clock start ticking earlier among women? The Western New York Study Diabetes Care 200730 354-359. (doi:10.2337/dc06-1772)

73 Rutter MK, Parise H, Benjamin EJ, Levy D, Larson MG, Meigs JB, Nesto RW, Wilson PW \& Vasan RS. Impact of glucose intolerance and insulin resistance on cardiac structure and function: sex-related differences in the Framingham Heart Study. Circulation 2003107 448-454. (doi:10.1161/01.CIR.0000045671.62860.98)

Received 18 May 2014

Revised version received 17 July 2014

Accepted 6 August 2014 